\title{
Recent Advances in Surface Plasmon Resonance Optical Sensors for Potential Application in Environmental Monitoring
}

\author{
Wan Mohd Ebtisyam Mustaqim Mohd Daniyal, ${ }^{1}$ Yap Wing Fen, ${ }^{1,2 *}$ \\ Nurul Illya Muhamad Fauzi, ${ }^{1}$ Hazwani Suhaila Hashim, ${ }^{2}$ \\ Nur Syahira Md Ramdzan, ${ }^{2}$ and Nur Alia Sheh Omar $^{2}$ \\ ${ }^{1}$ Functional Devices Laboratory, Institute of Advanced Technology, Universiti Putra Malaysia, \\ 43400 Serdang, Selangor, Malaysia \\ ${ }^{2}$ Department of Physics, Faculty of Science, Universiti Putra Malaysia, 43400 Serdang, Selangor, Malaysia
}

(Received November 28, 2020; accepted December 9, 2020)

Keywords: surface plasmon resonance, optical sensor, metal ion, phenol, pesticides

Surface plasmon resonance (SPR) optical sensors are among the most promising sensors for use in various fields of sensing. Owing to their advantages, SPR optical sensors have attracted tremendous attention, especially for monitoring environmental pollutants, e.g., heavy metal ions, phenol, and pesticides. To further enhance their sensitivity and selectivity towards a specific target pollutant, the development of various active layers on top of a metal surface has been explored over the past two decades. This paper provides up-to-date information on advances in SPR optical sensors for detecting heavy metals, phenol, and pesticides, which have been discussed and summarized in chronological order. The systematic information on the detection of these pollutants using SPR optical sensors will give researchers guidelines for future developments in this area.

\section{Introduction}

Optical sensors are known to be among the most versatile sensing tools, with the ability to detect a wide range of targets such as temperature, pressure, radiation level, force, electric field, $\mathrm{pH}$, strain, chemical concentration, displacement, liquid level, displacement, humidity, magnetic field, acoustic field, and many more. An optical sensor works by measuring the changes in a light beam due to the alteration of the intensity of light, which may change its optical properties of phase, wavelength, polarization, and spectral distribution. In short, it is a device that measures the quantity of light and translates it into some form that is readable by the instrument. Surface plasmon resonance (SPR) sensors are versatile optical sensors that have received considerable attention since early 1990s. The SPR phenomenon was first observed by Wood in 1902, when he observed a pattern of white and dark bands as he shone a monochromatic polarized light on a mirror with a diffraction grating on its surface. ${ }^{(1)}$ A complete physical interpretation of this phenomenon was not available until 1968, when Otto

*Corresponding author: e-mail: yapwingfen@gmail.com https://doi.org/10.18494/SAM.2020.3204 
and Kretschmann independently reported the excitation of surface plasmons. Since then, SPR has slowly made its way into the limelight owing to its practical applications in sensitive sensors, first emerging in a paper on gas sensing and biosensing in 1983. ${ }^{(2)}$

The Kretschmann configuration is the most common setup used for SPR optical sensors. In this configuration, monochromatic and p-polarized light is used to form a surface plasmon that propagates along a metal surface. At a certain angle known as the resonance angle, the intensity of the reflected light decreases owing to resonance, which occurs when the momentum of the surface plasmon wave is equivalent to that of the incident light. An SPR optical sensor works by measuring the refractive index near the metal surface. Any changes in refractive index will also change the resonance angle. Hence, SPR can be used as an optical sensor. However, SPR cannot be used to distinguish solutions with the same refractive index. Over the past two decades, research has been carried out to improve the sensitivity of SPR sensors for sensing applications either by the modification of the SPR system or by combination with various sensing methods. ${ }^{(3-8)}$ Another approach has been to modify the metal thin film surface with an active layer or a sensing element. The development of an improved active layer is crucial as it determines the optical sensor sensitivity, selectivity, and other parameters of sensors. SPR sensors with different active layers have been studied for various sensing applications including environment monitoring and clinical diagnosis. ${ }^{(9-11)}$ This paper reviews the development of active layers for SPR optical sensors as potential optical sensors for sensing environmental pollutants including heavy metal ions, phenol, and pesticides, as illustrated in Fig. 1. The detection limit, sensitivity, and selectivity of these active layers in combination with SPR sensing for environmental pollutants have been reviewed and summarized.

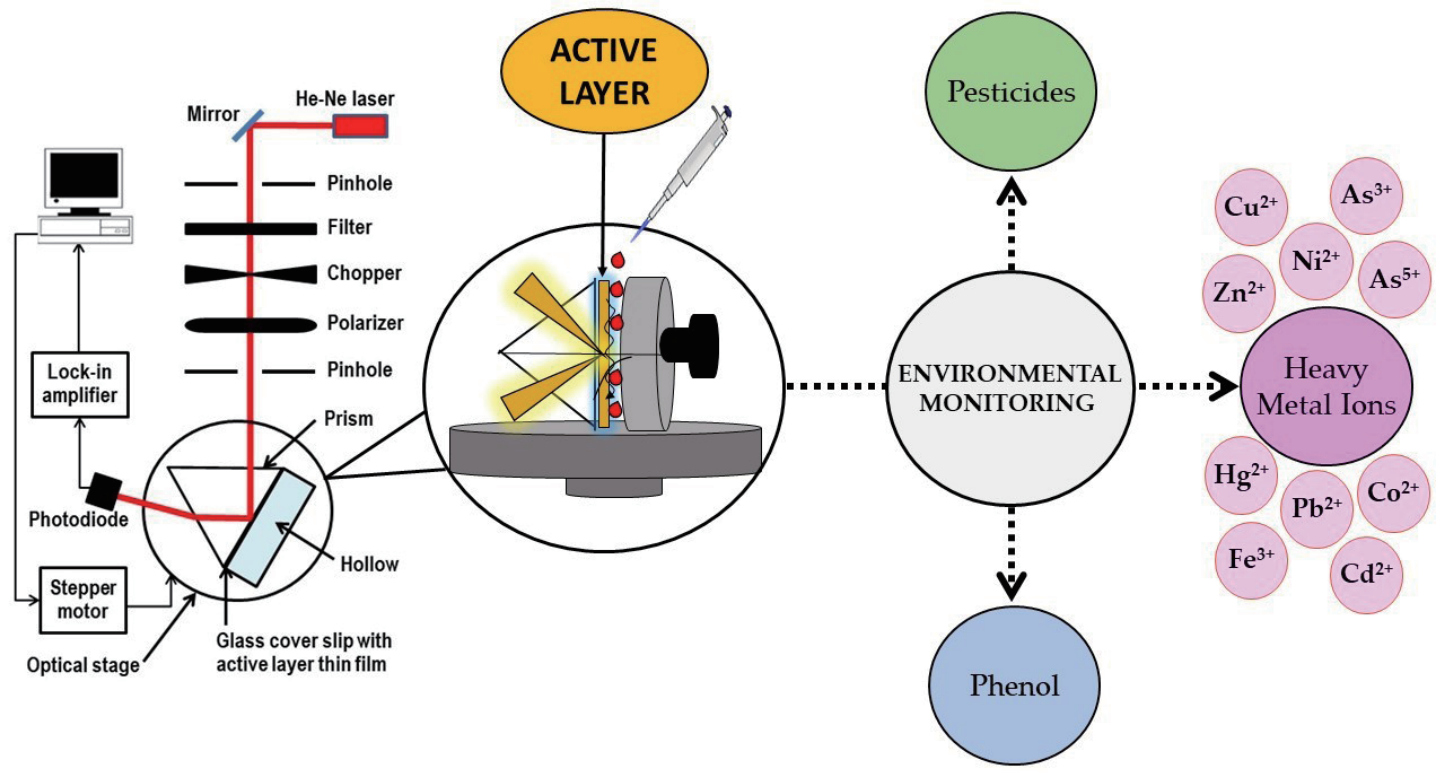

Fig. 1. (Color online) Schematic illustration of SPR optical sensor incorporating active layer for environmental monitoring. 


\section{Advantages of Using SPR for Sensing}

The most practical application and commercial use of SPR are based on the Kretschmann configuration, where a gold thin film is placed at the interface of two dielectric media, i.e., a prism and air or the solution of interest. The gold thin film with a thickness of $50 \mathrm{~nm}$ is deposited on a $24 \times 24 \mathrm{~mm}$ glass cover slip. The SPR setup (Fig. 1) consists of a He-Ne laser with a wavelength of $632.8 \mathrm{~nm}$, a prism with a high refractive index (greater than 1.60), an optical stage driven by a stepper motor (Newport MM 3000), a photodetector, and a lock-inamplifier (SR 530). The SPR optical sensor measures the resonance angle of the reflected light from the gold thin film. Any changes in the refractive index of the thin film surface will also change the resonance angle. By modifying the gold thin film surface with an active layer, any binding interaction between target analytes and the active layer can be detected rapidly in real time. This also gives the SPR optical sensor many advantages that include costeffectiveness, simple sample preparation, no need for a reference solution, label-free sensing, excellent sensitivity, and high selectivity towards target analytes. Moreover, information on the concentration of the analytes, the kinetics, and the affinity of the interaction can be obtained from the binding rates and levels of the SPR sensor. Other existing optical sensors, such as colorimetric, electrochemiluminescence, fluorescence, and optical fiber sensors, have great performance in detecting low concentrations of environmental pollutants, ${ }^{(12,13)}$ yet have one or more disadvantages among high cost, cumbersome operation, and time-consuming sensing. SPR also offers more advantages than conventional methods, such as atomic absorption spectroscopy (AAS), anodic stripping voltammetry (ASV), inductively coupled plasma-mass spectrometry (ICPMS), and X-ray fluorescence (XRF) spectroscopy, which have limitations including time-consuming sensing, complicated processing, and high-cost instruments. ${ }^{(14)}$ It is thus believed that SPR is more practical for the in situ remote sensing of environmental pollutants and chemical and biological analyses.

\section{SPR for Environmental Monitoring}

\subsection{Heavy metal ion detection}

Heavy metal ions are very harmful to biological systems and can lead to short-term and long-term diseases in humans even in trace amounts. Therefore, it is crucial to detect trace amounts of heavy metal ions in environmental water through continuous monitoring. Heavy metal ions are present in many industries such as the plating, machine, and chemical industries. SPR sensors are optical sensors with many advantages such as simple sample preparation, rapid measurement, and cost-effectiveness. The most important finding in the development of SPR sensors has been the development of an active layer on top of a gold thin film surface to improve the sensitivity of sensors for heavy metal ion detection. Work on the development of the active layer for metal ion sensing from 2001 to 2017 was previously discussed in detail. ${ }^{(15)}$ A wide range of materials with positive-ion adsorption properties such as chitosan, carbon, graphene oxide, metal oxide, conducting polymers (e.g., polypyrrole and polyanilline), and 
ionophores have been exploited as base materials for active layer development. ${ }^{(16-48)}$ As a result, the developed active layers have improved the sensitivity of SPR optical sensors for metal ion detection down to the ppb level. Nevertheless, studies on novel active layers for SPR sensing are still ongoing to further improve the sensitivity and selectivity of SPR sensors. For instance, Saleviter et al. (2018) deposited a 4-(2-pyridylazo)resorcinol-chitosan-graphene oxide composite on top of a gold thin film as an active layer for an SPR optical sensor. This material has high sensitivity to $\mathrm{Co}^{2+}$. Their optical sensor was able to detect $\mathrm{Co}^{2+}$ at a concentration of as low as $0.01 \mathrm{ppm}$ with a sensitivity of $0.00069^{\circ} \mathrm{ppm}^{-1}$ (49) $^{(4)}$ In the same year, Saleviter et al. employed a different active layer, namely, a cadmium sulfide quantum dot-graphene oxidechitosan composite, on a gold thin film in a further attempt to detect low $\mathrm{Co}^{2+}$ concentrations. ${ }^{(50)}$ The optical sensor was also able to detect $\mathrm{Co}^{2+}$ at a low concentration of $0.01 \mathrm{ppm}$. In another interesting work, Daniyal and coworkers (2018) developed an SPR optical sensor by incorporating a nanocrystalline cellulose-graphene oxide nanocomposite into an SPR system. ${ }^{(51,52)}$ This optical sensor was able to detect $\mathrm{Cu}^{2+}$ and $\mathrm{Ni}^{2+}$ at a concentration of $0.01 \mathrm{ppm}$ and had sensitivities of 3.271 and $1.509^{\circ} \mathrm{ppm}^{-1}$ for $\mathrm{Cu}^{2+}$ and $\mathrm{Ni}^{2+}$, respectively.

In 2019, Ramdzan et al. attempted to sense one of the most toxic metal ions, $\mathrm{Hg}^{2+}$. (53) They developed a chitosan/carboxyl-functionalized graphene quantum dot thin film and combined it with an SPR optical sensor. The sensor has high potential for sensing $\mathrm{Hg}^{2+}$ with a detection limit of $0.5 \mathrm{ppm}$. During the same year, Roshidi et al. also investigated $\mathrm{Hg}^{2+}$ detection ${ }^{(54)}$ using a graphene oxide/poly(amidoamine) dendrimer as an active layer, which was very good for sensing $\mathrm{Hg}^{2+}$, with a reported detection limit of $1 \mathrm{ppm}$. They then developed another material, namely, a chitosan-poly(amidoamine) dendrimer, to detect $\mathrm{Pb}^{2+}$ using an SPR optical sensor. ${ }^{(55)}$ The incorporation of the chitosan-poly(amidoamine) dendrimer in the SPR optical sensor improved its performance in sensing $\mathrm{Pb}^{2+}$, where the detection limit was $0.1 \mathrm{ppm}$. On the other hand, the use of a hydrous ferric oxide-magnetite-reduced graphene oxide active layer was reported by Al-rekabi et al. ${ }^{(56)}$ The thin film they developed was used to detect $\mathrm{As}^{3+}$ and $\mathrm{As}^{5+}$ at a very low concentration of $0.1 \mathrm{ppb}$. Their SPR optical sensor also had a higher sensitivity to $\mathrm{As}^{3+}$ than to $\mathrm{As}^{5+}$. They also investigated the selectivity of the developed active layer. The sensor had high selectivity towards $\mathrm{As}^{3+}$ when tested with a mixture of other heavy metal ions that included $\mathrm{Cr}^{2+}, \mathrm{Ni}^{2+}, \mathrm{Zn}^{2+}$, and $\mathrm{Mn}^{2+}$. Also in 2019, Daniyal et al. broadened their research from that in the previous year to detect other metal ions. ${ }^{(57)}$ Their SPR optical sensor using nanocrystalline cellulose-graphene oxide as an active layer was found to also detect $\mathrm{Zn}^{2+}$ at a concentration of as low as $0.01 \mathrm{ppm}$ in addition to $\mathrm{Cu}^{2+}$ and $\mathrm{Ni}^{2+}$.

In the following year, Zhao et al. deposited a germanium selenide (GeSe)-chitosan composite on top of a gold thin film. ${ }^{(58)}$ Their SPR optical sensor was able to detect $\mathrm{Pb}^{2+}$ at a concentration of $0.097 \mathrm{nM}$. Soon after that, $\mathrm{Wu}$ et al. demonstrated the sensing of $\mathrm{Pb}^{2+}$ at a much lower concentration. ${ }^{(59)}$ Using DNAzyme-gold nanoparticles as an active layer, their SPR optical sensor was used to detect $\mathrm{Pb}^{2+}$ at a concentration of $80 \mathrm{pM}$ and also had high selectivity; $\mathrm{Pb}^{2+}$ was distinguished from other metal ions that included $\mathrm{Co}^{2+}, \mathrm{Cd}^{2+}, \mathrm{Cu}^{2+}, \mathrm{Fe}^{2+}, \mathrm{Ba}^{2+}$, and $\mathrm{Ni}^{2+}$. More recently, Anas et al. investigated $\mathrm{Fe}^{3+}$ detection using SPR. They modified a gold thin film with $\mathrm{CTAB} /$ hydroxylated graphene quantum dots to improve the SPR sensitivity, ${ }^{(60)}$ and their SPR optical sensor was able to detect $\mathrm{Fe}^{3+}$ at a concentration of $0.18 \mu \mathrm{M}$. In an 
additional work, they reported that their sensor can also be used for sensing $\mathrm{Zn}^{2+}$ and $\mathrm{Ni}^{2+}$ with a detection limit of $1.8 \mu \mathrm{M} .{ }^{(61)}$ Bakhshpour and Denizli (2020) deposited a Cd(II) ion-imprinted (IIP) thin film on three different thin films comprising poly(hydroxyethylmethacrylate) (pHEMA), pHEMA-based nanoparticles (poly-NPs), and gold nanoparticles (AuNPs) for the detection of $\mathrm{Cd}^{2+}$. $^{62)}$ The IIP pHEMA, poly-NPs, and AuNPs were able to detect $\mathrm{Cd}^{2+}$ with detection limits of 4.45, 0.89, and $0.089 \mathrm{nM}$, respectively. Moreover, all three thin films had high selectivity towards $\mathrm{Cd}^{2+}$ in the presence of other metal ions $\left(\mathrm{Cr}^{2+}, \mathrm{Pb}^{2+}\right.$, and $\left.\mathrm{Zn}^{2+}\right)$. Later that year, Sadrolhosseini et al. improved the sensitivity of the SPR optical sensor by depositing polypyrrole-graphene quantum dots on a metal thin film surface. ${ }^{(63)}$ Owing to the excellent properties of polypyrrole-graphene quantum dots, the SPR sensitivity was enhanced and their sensor detected $\mathrm{As}^{3+}, \mathrm{Hg}^{2+}$, and $\mathrm{Pb}^{2+}$ with detection limits of $0.67,0.25$, and $0.24 \mathrm{nM}$, respectively. In summary, SPR optical sensors have encouraged the development of new materials as the active layer for metal ion sensing. The active layer is very important as it can enhance the sensitivity and selectivity of the sensors. Table 1 shows all the recent active layers that have been developed for sensing heavy metal ions using SPR from 2018 to 2020.

\subsection{Phenol detection}

Phenol is one of the toxic phenolic compounds that can be harmful to plants, animals, and humans. ${ }^{(64-69)}$ Exposure to phenol over its permissible level can lead to symptoms such as

Table 1

Heavy metal ion detection using SPR optical sensor.

\begin{tabular}{|c|c|c|c|c|c|}
\hline Type of metal ion & Active layer & Limit of detection & Selectivity & Year & Ref. \\
\hline $\mathrm{Co}^{2+}$ & $\begin{array}{l}\text { 4-(2-pyridylazo)resorcinol- } \\
\text { chitosan-graphene oxide }\end{array}$ & $0.36 \mu \mathrm{M}$ & - & 2018 & 49 \\
\hline $\mathrm{Co}^{2+}$ & $\begin{array}{l}\text { Cadmium sulfide quantum } \\
\text { dots-graphene oxide-chitosan }\end{array}$ & $0.36 \mu \mathrm{M}$ & - & 2018 & 50 \\
\hline $\begin{array}{l}\mathrm{Cu}^{2+} \\
\mathrm{Ni}^{2+}\end{array}$ & Nanocrystalline cellulose-graphene oxide & $\begin{array}{l}0.16 \mu \mathrm{M} \\
0.17 \mu \mathrm{M}\end{array}$ & - & 2018 & 51,52 \\
\hline $\mathrm{Hg}^{2+}$ & $\begin{array}{l}\text { Chitosan/carboxyl-functionalized } \\
\text { graphene quantum dots }\end{array}$ & $2.49 \mu \mathrm{M}$ & - & 2019 & 53 \\
\hline $\mathrm{Hg}^{2+}$ & $\begin{array}{c}\text { Graphene oxide/poly(amidoamine) } \\
\text { dendrimer }\end{array}$ & $4.99 \mu \mathrm{M}$ & - & 2019 & 54 \\
\hline $\mathrm{Pb}^{2+}$ & Chitosan-poly(amidoamine) dendrimer & $0.48 \mathrm{nM}$ & - & 2019 & 55 \\
\hline $\begin{array}{l}\mathrm{As}^{3+} \\
\mathrm{As}^{5+}\end{array}$ & $\begin{array}{l}\text { Hydrous ferric oxide-magnetite-reduced } \\
\text { graphene oxide }\end{array}$ & $1.33 \mathrm{nM}$ & $\checkmark$ & 2019 & 56 \\
\hline $\mathrm{Zn}^{2+}$ & Nanocrystalline cellulose-graphene oxide & $0.15 \mu \mathrm{M}$ & - & 2019 & 57 \\
\hline $\mathrm{Pb}^{2+}$ & Germanium selenide (GeSe)-chitosan & $0.097 \mathrm{nM}$ & - & 2020 & 58 \\
\hline $\mathrm{Pb}^{2+}$ & DNAzyme-AuNPs & $80 \mathrm{pM}$ & $\checkmark$ & 2020 & 59 \\
\hline $\begin{array}{l}\mathrm{Fe}^{3+} \\
\mathrm{Zn}^{2+} \\
\mathrm{Ni}^{2+} \\
\end{array}$ & $\begin{array}{l}\text { CTAB/hydroxylated graphene } \\
\text { quantum dots }\end{array}$ & $\begin{array}{l}0.18 \mu \mathrm{M} \\
1.8 \mu \mathrm{M}\end{array}$ & - & 2020 & 60,61 \\
\hline $\mathrm{Cd}^{2+}$ & $\begin{array}{l}\text { IIP-pHEMA thin film } \\
\text { IIP-poly-NPs thin film } \\
\text { IIP-AuNPs thin film }\end{array}$ & $\begin{array}{l}4.45 \mathrm{nM} \\
0.89 \mathrm{nM} \\
0.089 \mathrm{nM} \\
\end{array}$ & $\checkmark$ & 2020 & 62 \\
\hline $\begin{array}{l}\mathrm{As}^{3+} \\
\mathrm{Hg}^{2+} \\
\mathrm{Pb}^{2+}\end{array}$ & $\begin{array}{l}\text { Polypyrrole-graphene } \\
\text { quantum dots }\end{array}$ & $\begin{array}{l}0.67 \mathrm{nM} \\
0.25 \mathrm{nM} \\
0.24 \mathrm{nM}\end{array}$ & - & 2020 & 63 \\
\hline
\end{tabular}


vomiting and diarrhea, and further exposure can cause kidney, lung, and liver malfunction. ${ }^{(70-75)}$ Consequently, it has drawn researchers' attention, leading to the rapid development of sensors for its detection. SPR sensors have emerged as novel sensors with high potential for detecting phenol.

The first work on the use of SPR for phenol detection was introduced by Singh et al. in 2013, who incorporated tyrosinase entrapped in polyacrylamide gel coated on a silver thin film as the sensing layer with a fiber-optic-based SPR optical sensor. A wide linear response was observed from 0 to $1000 \mu \mathrm{M}$ and a detection limit of $38 \mu \mathrm{M}$ was obtained. ${ }^{(76)}$ Next, in 2020, Hashim et al. coated a layer of tyrosinase mixed with graphene oxide on a gold thin film and used it in a prism-based SPR sensor for sensing phenol. The shift in resonance angle had a linear relationship with the phenol concentration in the range of $0-100 \mu \mathrm{M}$ with a detection limit of $1 \mu \mathrm{M}^{(77)}$ Table 2 shows the findings on phenol detection using an SPR sensor.

\subsection{Pesticide detection}

Over the past few years, pesticides such as synthetic insecticides have been widely used in agriculture, medicine, and industry and by consumers. The release of untreated effluent from these industries into the environment can lead to the accumulation of toxic pesticides, endangering both humans and the environment. ${ }^{(78)}$ Among the pesticides, insecticide residue analysis is a particularly important requirement to ensure food quality and safety, and protect ecosystems and humans from potential hazards. ${ }^{(79)}$

SPR optical sensors have emerged as effective sensors for sensing insecticides since 2006, when sensors were first used to detect carbaryl, DDT, and profenofos. ${ }^{(80-82)}$ Since then, the detection of other widely used insecticides such as chlorpyrifos, dimethoate, carbofuran, carbendazim, and fenitrothion has attracted the attention of researchers. For instance, Thepudom et al. (2018) demonstrated the detection of chlorpyrifos using SPR enhanced by photoelectrochemical sensing. AuNPs were deposited with a poly(3-hexylthiophene)-titanium dioxide ( $\left.\mathrm{P} 3 \mathrm{HT}-\mathrm{TiO}_{2}\right)$-functionalized gold grating layer then used to generate an SPR signal. Using the hybrid SPR enhancement system, chlorpyrifos was detected at a concentration as low as $7.5 \mathrm{nM}^{\left({ }^{83}\right)}$

In 2019, Li et al. reported the use of an SPR biosensor with an antibody-oriented assembly as an active layer to rapidly detect residues of chlorpyrifos in agricultural samples. They used a covalent-oriented strategy in which staphylococcal protein A (SPA) was covalently bonded to the surface of a gold thin film for the monitoring of chlorpyrifos residues. The SPA-modified biosensor had a low detection limit of $15.973 \mathrm{nM}$ for chlorpyrifos. It also exhibited excellent specificity for chlorpyrifos in cross-reactivity studies on a series of structural and functional

Table 2

Findings on phenol detection using SPR sensor.

\begin{tabular}{lccc}
\hline Material & Limit of detection & Year & Ref. \\
\hline Tyrosinase-polyacrylamide gel-silver thin film & $38 \mu \mathrm{M}$ & 2013 & 76 \\
Tyrosinase-graphene oxide-gold thin film & $1 \mu \mathrm{M}$ & 2020 & 77 \\
\hline
\end{tabular}


Table 3

Insecticide detection using SPR optical sensors.

\begin{tabular}{|c|c|c|c|c|c|}
\hline Type of insecticide & Material & Limit of detection & Selectivity & Year & Ref. \\
\hline Chlorpyrifos & $\mathrm{TiO}_{2} / \mathrm{P} 3 \mathrm{HT} / \mathrm{AuNPs}$ & $7.500 \mathrm{nM}$ & & 2018 & 80 \\
\hline Chlorpyrifos & SPA & $15.973 \mathrm{nM}$ & $\checkmark$ & 2019 & 81 \\
\hline $\begin{array}{l}\text { Dimethoate } \\
\text { Carbofuran }\end{array}$ & P(EGDMA-MATrp) & $\begin{array}{l}0.033 \mathrm{nM} \\
0.035 \mathrm{nM}\end{array}$ & $\checkmark$ & 2019 & 82 \\
\hline Carbendazim & $\mathrm{AuNPs}-\mathrm{Fe}_{3} \mathrm{O}_{4} / \mathrm{mAbs}$ & $2.301 \mathrm{nM}$ & $\checkmark$ & 2019 & 83 \\
\hline Fenitrothion & Tantalum(V) oxide nanoparticles & $0.038 \mu \mathrm{M}$ & $\checkmark$ & 2020 & 84 \\
\hline
\end{tabular}

analogues of chlorpyrifos, including chlorfenvinphos, bromophos-ethyl, dichlofenthion, and chlorpyrifos-methyl, indicating excellent selectivity for chlorpyrifos over other pesticides. ${ }^{(84)}$ Furthermore, Çakır and Baysal (2019) prepared SPR sensor chip nanofilms of p(EGDMAMATrp) polymer using a molecular imprinting method for the detection of dimethoate and carbofuran. The limits of detection of dimethoate and carbofuran were 0.033 and $0.035 \mathrm{nM}$, respectively. They also reported that SPR sensor chip nanofilms of p(EGDMA-MATrp) polymer had high selectivity towards dimethoate and carbofuran when tested with other insecticides such as parathion, monocrotophos, bendiocarb, and carbaryl. ${ }^{(85)}$ Next, Li et al. (2019) reported an SPR biosensor for carbendazim that had enhanced performance due to the use of a $\mathrm{Au} / \mathrm{Fe}_{3} \mathrm{O}_{4}$ nanocomposite as an amplifying label on the surface of a carboxymethyldextrancoated gold layer of the sensor. To realize a sensor for the real-time detection of carbendazim, the surface was further modified with a monoclonal antibody. According to their report, the sensor had good specificity in carbendazim determination when tested with benzimidazole, 2-(2-aminoethyl)benzimidazole, 2-benzimidazole propionic acid, and 2-mercaptobenzimidazole. The limit of detection obtained for carbendazim was $2.301 \mathrm{nM}^{(86)}$

Lastly, Kant (2020) conducted a study on fenitrothion detection using SPR. They used tantalum(V) oxide nanoparticles sequestered in a nanoscale matrix of reduced graphene oxide as the sensing layer. Instead of a gold thin film, the sensing layer was deposited on top of a thin layer of silver. The limit of detection they obtained for fenitrothion detection was $0.038 \mu \mathrm{M}$. The selectivity for fenitrothion was obtained by comparing the shift attained at the resonance wavelength corresponding to the minimum (generally the blank concentration) and maximum concentrations of the target analyte with other interferents. The results showed that there was no appreciable influence on selectivity even when the interferents had a 10 -fold higher concentration. ${ }^{(87)}$ Table 3 shows all the active layers of SPR optical sensors used for the detection of insecticides such as chlorpyrifos, dimethoate, carbofuran, carbendazim, and fenitrothion in chronological order.

\section{Conclusion}

This paper has reviewed recent trends in SPR optical sensors for the potential sensing of environmental pollutants. Various modifications of a metal thin film surface with an active layer to improve the sensitivity and selectivity of the optical sensors have been discussed in detail. To conclude, SPR optical sensors have attracted interest and encouraged the development 
of new materials as active layers for detecting environmental pollutants owing to the advantages of SPR. The development of new active layers is very important as they determine the sensitivity, selectivity, and other parameters of optical sensors. SPR optical sensors have high potential in sensing environmental pollutants at concentrations as low as pM to $\mu \mathrm{M}$. Moreover, the concentration of pollutants can be measured in real time with small samples. We expect that further research on SPR optical sensors will improve their sensing capabilities, enabling costeffective, rapid, sensitive, and selective analysis to be widely used in environmental monitoring.

\section{References}

1 R. W. Wood: Proc. Phys. Soc. London 18 (1902) 269. https://doi.org/10.1088/1478-7814/18/1/325

2 B. Liedberg, C. Nylander, and I. Lunström: Sens. Actuators 4 (1983) 299. https://doi.org/10.1080/13662716.201 7.1395730

3 N.-S. Eum, S.-H. Lee, D.-R. Lee, D.-K. Kwon, J.-K. Shin, J.-H. Kim, and S.-W. Kang: Sens. Actuators, B 96 (2003) 446. https://doi.org/10.1016/S0925-4005(03)00599-9

4 S. Wang, E. S. Forzani, and N. Tao: Anal. Chem. 79 (2007) 4427. https://doi.org/10.1021/ac0621773

5 H. Chen, Y. Lee, M.-C. Oh, J. Lee, S.-C. Ryu, Y.-H. Hwang, and K. Koh: Sens. Actuators, B 134 (2008) 419. https://doi.org/10.1016/j.snb.2008.05.017

6 Y. M. Panta, J. Liu, M. A. Cheney, S. W. Joo, and S. Qian: J. Colloid Interface Sci. 333 (2009) 485. https://doi. org/10.1016/j.jcis.2009.02.026

7 Y. W. Fen and W. M. M. Yunus: Sens. Rev. 33 (2013) 305. https://doi.org/10.1108/SR-01-2012-604

8 J. Castillo, J. Chirinos, H. Gutiérrez, and M. La Cruz: Opt. Laser Technol. 94 (2017) 34. https://doi.org/10.1016/ j.optlastec.2017.03.013

9 N. A. S. Omar, Y. W. Fen, S. Saleviter, W. M. E. M. M. Daniyal, N. A. A. Anas, N. S. M. Ramdzan, and M. D. A. Roshidi: Materials 12 (2019) 1. https://doi.org/10.3390/ma12121928

10 N. A. S. Omar, Y. W. Fen, J. Abdullah, Y. M. Kamil, W. M. E. M. M. Daniyal, A. R. Sadrolhosseini, and M. A. Mahdi: Sci. Rep. 10 (2020) 1. https://doi.org/10.1038/s41598-020-59388-3

11 N. A. S. Omar, Y. W. Fen, J. Abdullah, M. H. M. Zaid, W. M. E. M. M. Daniyal, and M. A. Mahdi: Opt. Laser Technol. 114 (2019) 204. https://doi.org/10.1016/j.optlastec.2019.01.038

12 N. S. M. Ramdzan, Y. W. Fen, N. A. A. Anas, N. A. S. Omar, and S. Saleviter: Molecules 25 (2020) 1. https:// doi.org/10.3390/molecules25112548

13 R. Raghunandhan, L. H. Chen, H. Y. Long, L. L. Leam, P. L. So, X. Ning, and C. C. Chan: Sens. Actuators, B 233 (2016) 31. https://doi.org/10.1016/j.snb.2016.04.020

14 N. A. A. Anas, Y. W. Fen, N. A. S. Omar, W. M. E. M. M. Daniyal, N. S. M. Ramdzan, and S. Saleviter: Sensors 19 (2019) 1. https://doi.org/10.3390/s19183850

15 W. M. E. M. M. Daniyal, S. Saleviter, and Y. W. Fen: Sens. Mater. 30 (2018) 2023. https://doi.org/10.18494/ SAM.2018.1952

16 K. Ock, G. Jang, Y. Roh, S. Kim, J. Kim, and K. Koh: Microchem. J. 70 (2001) 301. https://doi.org/10.1016/ S0026-265X(01)00133-3

17 S. M. Lee, S. W. Kang, D. U. Kim, J. Z. Cui, and S. H. Kim: Dye. Pigment. 49 (2001) 109. https://doi. org/10.1016/S0143-7208(01)00017-1

18 Y. Hur, K. Ock, K. Kim, S. Jin, Y. Gal, J. Kim, S. Kim, and K. Koh: Anal. Chim. Acta 460 (2002) 133. https:// doi.org/10.1016/S0003-2670(02)00146-0

19 L. M. May and D. A. Russell: Anal. Chim. Acta 500 (2003) 119. https://doi.org/10.1016/S0003-2670(03)009437

20 S. Chah, J. Yi, and R. N. Zare: Sens. Actuators, B 99 (2004) 216. https://doi.org/10.1016/j.snb.2003.11.015

21 J. C. C. Yu, E. P. C. Lai, and S. Sadeghi: Sens. Actuators, B 101 (2004) 236. https://doi.org/10.1016/ j.snb.2004.03.007

22 C. M. Wu and L. Y. Lin: Biosens. Bioelectron. 20 (2004) 863. https://doi.org/10.1016/j.bios.2004.03.026

23 C. M. Wu and L. Y. Lin: Sens. Actuators, B 110 (2005) 231. https://doi.org/10.1016/j.snb.2005.01.047

24 E. S. Forzani, H. Zhang, W. Chen, and N. Tao: Environ. Sci. Technol. 39 (2005) 1257. https://doi.org/10.1021/ es049234

25 J. Moon, T. Kang, S. Oh, S. Hong, and J. Yi: J. Colloid Interface Sci. 298 (2006) 543. https://doi.org/10.1016/ j.jcis.2005.12.066 
26 Y. Zhang, M. Xu, Y. Wang, F. Toledo, and F. Zhou: Sens. Actuators, B 123 (2007) 784. https://doi.org/10.1016/ j.snb.2006.10.019

27 E. S. Forzani, K. Foley, P. Westerhoff, and N. Tao: Sens. Actuators, B 123 (2007) 82. https://doi.org/10.1016/ j.snb.2006.07.033

28 S. Hong, T. Kang, J. Moon, S. Oh, and J. Yi: Colloids Surf. A Physicochem. Eng. Asp. 292 (2007) 264. https:// doi.org/10.1016/j.colsurfa.2006.06.031

29 H. Chen, Y.-S. Gal, S.-H. Kim, H.-J. Choi, M.-C. Oh, J. Lee, and K. Koh: Sens. Actuators, B 133 (2008) 577. https://doi.org/10.1016/j.snb.2008.03.038

30 K. J. Fahnestock, M. Manesse, H. A. McIlwee, C. L. Schauer, R. Boukherroub, and S. Szunerits: Analyst 134 (2009) 881. https://doi.org/10.1039/b817140h

31 L. Wang, T. Li, Y. Du, C. Chen, B. Li, M. Zhou, and S. Dong: Biosens. Bioelectron. 25 (2010) 2622. https://doi. org/10.1016/j.bios.2010.04.027

32 C. C. Chang, S. Lin, S. C. Wei, C. Y. Chen, and C. W. Lin: Biosens. Bioelectron. 30 (2011) 235. https://doi. org/10.1016/j.bios.2011.09.018

33 Y. W. Fen, W. M. M. Yunus, and N. A. Yusof: Sens. Mater. 23 (2011) 325. https://doi.org/10.18494/ SAM.2011.723

34 Y. W. Fen, W. M. M. Yunus, and N. A. Yusof: Sens. Lett. 9 (2011) 1704. https://doi.org/10.1166/sl.2011.1742

35 M. M. Abdi, L. C. Abdullah, A. R. Sadrolhosseini, W. M. Mat Yunus, M. M. Moksin, and P. M. Tahir: PLoS One 6 (2011) e24578. https://doi.org/10.1371/journal.pone.0024578

36 Y. W. Fen and W. M. M. Yunus: IEEE Sens. J. 13 (2012) 1413. https://doi.org/10.1109/jsen.2012.2235311

37 Y. W. Fen, W. M. M. Yunus, and N. A. Yusof: Sens. Actuators, B 171 (2012) 287. https://doi.org/10.1016/ j.snb.2012.03.070

38 G. Pelossof, R. Tel-Vered, and I. Willner: Anal. Chem. 84 (2012) 3703. https://doi.org/10.1021/ac3002269

39 E. J. Kim, B. H. Chung, and H. J. Lee: Anal. Chem. 84 (2012) 10091. https://doi.org/10.1021/ac302584d

40 Y. W. Fen, W. M. M. Yunus, and Z. A. Talib: Optik 124 (2013) 126. https://doi.org/10.1016/j.ijleo.2011.11.035

41 A. R. Sadrolhosseini, A. S. M. Noor, A. Bahrami, H. N. Lim, Z. A. Talib, and M. A. Mahdi: PLoS One 9 (2014) e93962. https://doi.org/10.1371/journal.pone.0093962

42 N. F. Lokman, A. A. A. Bakar, F. Suja, H. Abdullah, W. B. W. A. Rahman, N. M. Huang, and M. H. Yaacob: Sens. Actuators, B 195 (2014) 459. https://doi.org/10.1016/j.snb.2014.01.074

43 Y. W. Fen, W. M. M. Yunus, Z. A. Talib, and N. A. Yusof: Spectrochim. Acta A Mol. Biomol. Spectrosc. 134 (2015) 48. https://doi.org/10.1016/j.saa.2014.06.081

44 R. Verma and B. D. Gupta: Food Chem. 166 (2015) 568. https://doi.org/10.1016/j.foodchem.2014.06.045

45 D. Peralta-Domínguez, M. Rodriguez, G. Ramos-Ortiz, J. L. Maldonado, D. Luna-Moreno, M. OrtizGutierrez, and V. Barba: Sens. Actuators, B 225 (2016) 221. https://doi.org/10.1016/j.snb.2015.11.013

46 A. R. Sadrolhosseini, M. Naseri, and S. A. Rashid: Opt. Laser Technol. 93 (2017) 216. https://doi.org/10.1016/ j.optlastec.2017.03.008

47 A. A. Zainudin, Y. W. Fen, N. A. Yusof, S. H. Al-Rekabi, M. A. Mahdi, and N. A. S. Omar: Spectrochim. Acta A Mol. Biomol. Spectrosc. 191 (2018) 111. https://doi.org/10.1016/j.saa.2017.10.013

48 N. H. Kamaruddin, A. A. A. Bakar, M. H. Yaacob, M. A. Mahdi, M. S. D. Zan, and S. Shaari: Appl. Surf. Sci. 361 (2016) 177. https://doi.org/10.1016/j.apsusc.2015.11.099

49 S. Saleviter, Y. W. Fen, N. A. Sheh Omar, W. M. E. M. M. Daniyal, J. Abdullah, and M. A. Mahdi: Sens. Mater. 32 (2020) 2877. https://doi.org/10.18494/SAM.2020.2858

50 S. Saleviter, Y. W. Fen, N. A. S. Omar, W. M. E. M. M. Daniyal, J. Abdullah, and M. H. M. Zaid: J. Nanomater. 2018 (2018) 4324072. https://doi.org/10.1155/2018/4324072

51 W. M. E. M. M. Daniyal, Y. W. Fen, J. Abdullah, A. R. Sadrolhosseini, S. Saleviter, and N. A. S. Omar: Opt. Express 26 (2018) 34880. https://doi.org/oe-26-26-34880

52 W. M. E. M. M. Daniyal, Y. W. Fen, J. Abdullah, A. R. Sadrolhosseini, S. Saleviter, and N. A. S. Omar: Spectrochim. Acta A Mol. Biomol. Spectrosc. 212 (2019) 25. https://doi.org/S1386142518311016

53 N. S. M. Ramdzan, Y. W. Fen, N. A. S. Omar, N. A. A. Anas, W. M. E. M. M. Daniyal, S. Saleviter, and A. A. Zainudin: Optik 178 (2019) 802. https://doi.org/10.1016/j.ijleo.2018.10.071

54 M. D. A. Roshidi, Y. W. Fen, N. A. S. Omar, S. Saleviter, and W. M. E. M. M. Daniyal: Sens. Mater. 31 (2019) 1147. https://doi.org/10.18494/SAM.2019.2142

55 M. D. A. Roshidi, Y. W. Fen, W. M. E. M. M. Daniyal, N. A. S. Omar, and M. Zulholinda: Optik 185 (2019) 351. https://doi.org/10.1016/j.ijleo.2019.03.118

56 S. H. Al-rekabi, Y. M. Kamil, M. H. A. Bakar, Y. W. Fen, H. N. Lim, S. Kanagesan, and M. A. Mahdi: Opt. Laser Technol. 111 (2019) 417. https://doi.org/10.1016/j.optlastec.2018.10.018

57 W. M. E. M. M. Daniyal, Y. W. Fen, N. A. A. Anas, N. A. S. Omar, N. S. M. Ramdzan, H. Nakajima, and M. A. Mahdi: RSC Adv. 9 (2019) 41729. https://doi.org/10.1039/c9ra07368j 
58 Y. Zhao, S. Gan, L. Wu, J. Zhu, Y. Xiang, and X. Dai: Nanophotonics 9 (2020) 327. https://doi.org/10.1515/ nanoph-2019-0170

59 H. Wu, S. Wang, S. F. Y. Li, Q. Bao, and Q. Xu: Anal. Bioanal. Chem. 412 (2020) 7525. https://doi.org/10.1007/ s00216-020-02887-Z

60 N. A. A. Anas, Y. W. Fen, N. A. Yusof, N. A. S. Omar, W. M. E. M. M. Daniyal, and N. S. M. Ramdzan: J. Appl. Phys. 128 (2020) 1. https://doi.org/10.1063/5.0018106

61 N. A. A. Anas, Y. W. Fen, N. A. Yusof, N. A. S. Omar, N. S. M. Ramdzan, and W. M. E. M. M. Daniyal: Materials 13 (2020) 2591. https://doi.org/10.3390/ma13112591

62 M. Bakhshpour and A. Denizli: Microchem. J. 159 (2020) 105572. https://doi.org/10.1016/j.microc.2020.105572

63 A. R. Sadrolhosseini, S. Shafie, S. A. Rashid, and M. A. Mahdi: Measurement 108546 (2020) 1. https://doi. org/10.1016/j.measurement.2020.108546

64 J. Abdullah, M. Ahmad, Y. H. Lee, N. Karuppiah, and H. Sidek: Sensors 7 (2007) 2238. https://doi. org $/ 10.3390 / \mathrm{s} 7102238$

65 A. A. Gami, M. Y. Shukor, K. A. Khalil, F. A. Dahalan, A. Khalid, and S. A. Ahmad: J. Environ. Microbiol. Toxicol. 2 (2014) 11. http://journal.hibiscuspublisher.com/index.php/JEMAT/article/view/89

66 D. A. Oriero, I. O. Gyan, B. W. Bolshaw, I. F. Cheng, and D. E. Aston: Microchem. J. 118 (2015) 166. https:// doi.org/10.1016/j.microc.2014.09.005

67 F. A. A. Manan, W. W. Hong, J. Abdullah, N. A. Yusof, and I. Ahmad: Mater. Sci. Eng. C 99 (2019) 37. https:// doi.org/10.1016/j.msec.2019.01.082

68 M. Sun, Y. Bu, J. Feng, and C. Luo: J. Sep. Sci. 39 (2016) 375. https://doi.org/10.1002/jssc.201500904

69 X. Ji, J. Hong, and X. Guo: Analyst 137 (2012) 710. https://doi.org/10.1039/clan15647k

70 L. Jiang, I. Santiago, and J. Foord: Commun. Chem. 1 (2018) 1. https://doi.org/10.1038/s42004-018-0045-8

71 S. Noh and H. Yang: Electroanalysis 26 (2014) 2727. https://doi.org/10.1002/elan.201400383

72 N. M. Ahmad, J. Abdullah, N. A. Yusof, A. H. Ab Rashid, S. A. Rahman, and M. R. Hasan: Biosensors 6 (2016) 1. DOI:10.3390/bios6030031

73 M. N. Karim and H. J. Lee: Talanta 116 (2013) 991. https://doi.org/10.1016/j.talanta.2013.08.003

74 M. Topcu Sulak, E. Erhan, and B. Keskinler: Appl. Biochem. Biotechnol. 160 (2010) 856. https://doi. org/10.1007/s12010-009-8534-y

75 H. S. Hashim, Y. W. Fen, N. A. S. Omar, W. M. E. M. M. Daniyal, S. Saleviter, and J. Abdullah: Optik 212 (2020) 164786. https://doi.org/10.1016/j.ijleo.2020.164786

76 S. Singh, S. K. Mishra, and B. D. Gupta: Sens. Actuators, B 186 (2013) 388. https://doi.org/10.1016/ j.snb.2013.06.034

77 H. S. Hashim, Y. W. Fen, N. A. Sheh Omar, J. Abdullah, W. M. E. M. M. Daniyal, and S. Saleviter: Opt. Express 28 (2020) 9738. https://doi.org/10.1364/oe.387027

78 A. M. Shrivastav, S. P. Usha, and B. D. Gupta: Biosens. Bioelectron. 79 (2016) 150. https://doi.org/10.1016/ j.bios.2015.11.095

79 G. H. Yao, R. P. Liang, C. F. Huang, Y. Wang, and J. D. Qiu: Anal. Chem. 85 (2013) 11944. https://doi. org/10.1021/ac402848x

80 E. Mauriz, A. Calle, A. Abad, A. Montoya, A. Hildebrandt, D. Barceló, and L. M. Lechuga: Biosens. Bioelectron. 21 (2006) 2129. https://doi.org/10.1016/j.bios.2005.10.013

81 E. Mauriz, A. Calle, J. J. Manclús, A. Montoya, and L. M. Lechuga: Anal. Bioanal. Chem. 387 (2007) 1449. https://doi.org/10.1007/s00216-006-0800-Z

82 J. Dong, N. Gao, Y. Peng, C. Guo, Z. Lv, Y. Wang, C. Zhou, B. Ning, M. Liu, and Z. Gao: Food Control 25 (2012) 543. https://doi.org/10.1016/j.foodcont.2011.11.015

83 T. Thepudom, C. Lertvachirapaiboon, K. Shinbo, K. Kato, F. Kaneko, T. Kerdcharoen, and A. Baba: MRS Commun. 8 (2018) 107. https://doi.org/10.1557/mrc.2017.131

84 Q. Li, X. Dou, L. Zhang, X. Zhao, J. Luo, and M. Yang: Anal. Bioanal. Chem. 411 (2019) 6057. https://doi. org/10.1007/s00216-019-01990-0

85 O. Çakır and Z. Baysal: Sens. Actuators, B 297 (2019) 126764 https://doi.org/10.1016/j.snb.2019.126764

86 Q. Li, X. Dou, X. Zhao, L. Zhang, J. Luo, X. Xing, and M. Yang: Microchim. Acta 186 (2019) 4. https://doi. org/10.1007/s00604-019-3402-0

87 R. Kant: Microchim. Acta 187 (2020) 1. https://doi.org/10.1007/s00604-019-4002-8 